\title{
环渤海地区城市人居环境质量评估及 影响因素
}

\author{
陈呈奕 ${ }^{1,2}$, 张文忠 ${ }^{1 *}$, 湛东升 ${ }^{1,2}$, 李雪丽 ${ }^{3}$ \\ (1. 中国科学院地理科学与资源研究所, 北京 $100101 ; 2$. 中国科学院大学, 北京 100049 ; \\ 3. 上海财经大学国际工商管理学院, 上海 200433)
}

\begin{abstract}
摘 要: 城市人居环境是城市居民生活质量和满意度的重要内容。本文以环渤海地区 44 个城市为例, 从人居硬环 境和软环境两方面评价人居环境指数, 运用描述统计和 GIS 制图方法, 分析环渤海地区城市人居环境综合质量空 间差异及其影响因素, 研究发现: 1)人居环境综合指数存在显著空间差异, 沿海城市的人居环境质量明显高于内陆 城市; 在省级行政单元中, 辽宁省人居环境综合指数最高, 天津最低。(2)环渤海地区城市人居环境指数与经济发展 水平和城镇化水平不存在显著的正相关关系, 但与人口规模存在显著的负相关关系, 表明仅提升经济发展水平和 城市化率并不能提升城市人居环境质量,但合理控制城市人口规模则可有助于提升城市人居环境质量。
\end{abstract}

关 键 词: 人居环境; 环渤海地区; 综合评价; 社会经济驱动力

\section{1 引言}

随着改革开放的推进, 中国的社会经济发展取 得了显著成效。统计资料显示, 2015 年中国人均 GDP 开始超过 8000 美元。按照世界银行的划分标 准, 中国已属于中等偏上收人国家; 按照钱纳里工 业化阶段理论的划分标准, 中国则进人工业化的后 期阶段。虽然近几十年来中国粗放型经济发展模 式促使国民经济快速发展, 但同时也带来了日益严 峻的生态和环境问题, 严重影响到城市人居环境和 居民生活满意度(张文忠等, 2013)。随着中国城市 居民对居住环境需求的提升, 城市人居环境质量越 来越成为政府和社会共同关注的重要课题。因此, 加强城市人居环境建设和提高居民人居环境满意 度已成为政府和民众共同的期望。

人居环境学科是希腊学者 Doxiadis 于 20 世纪 50 年代提出的(Doxiadis, 1975)。自 1976年第一次
人类居住大会发表《温哥华宣言》(United Nations, 1976), 人居环境开始作为一门独立的学科被越来 越多的学者所认识。在人居环境研究进展方面, 国 外学者比较注重评价内容的扩展和深人, 将性别 (Reeves, 2014)、低收人群体(Charoenkit et al, 2014)、 环境卫生(Castro et al, 2015; Tsinda et al, 2015)、健 康状况(Yen et al, 1999; McNeill et al, 2006; Jackson et al, 2013)、交通(Schetke et al, 2012)、自然灾害以及 环境目标(Sebti et al, 2013)等多方面因素纳人人居 环境质量评估体系。

20 世纪 90 年代, 吴良镛院士首次在国内倡导 建立人居环境科学, 并提出人居环境由自然系统、 人类系统、社会系统、居住系统和支撑系统等 5 个子 系统组成,包括全球、区域、城市、社区(村镇)、建筑 等 5 个层次的研究(吴良镛, 2001)。随后, 国内许多 学者对人居环境开展了多方面研究, 内容涉及人居 环境的科学基础(汪洋等, 2012)、空间分异(谷永泉

收稿日期: 2017-07; 修订日期: 2017-10。

基金项目: 国家自然科学基金重点项目(41230632)[Foundation: Key Project of National Natural Science Foundation of China, No.41230632]。

作者简介: 陈呈奕(1995-), 男,山东泰安人,博士研究生, 主要从事人居环境研究,E-mail: chenchengyi16@ mails.ucas.ac.cn。

通讯作者: 张文忠(1966-), 男,内蒙古呼和浩特人,博士,研究员,主要从事城市和区域发展等研究,E-mail: zhangwz@igsnrr.ac.cn。

引用格式: 陈呈奕, 张文忠, 湛东升, 等. 2017. 环渤海地区城市人居环境质量评估及影响因素[J]. 地理科学进展, 36(12): 1562-1570. [Chen C Y, Zhang W Z, Zhan D S, et al. 2017. Quantitative evaluation of human settlement environment and influencing factors in the Bohai Rim area[J]. Progress in Geography, 36(12): 1562-1570.]. DOI: 10.18306/dlkxjz.2017.12.011 
等, 2015; 朱涁等, 2015)、演变因素(祁新华等, 2008; 李伯华等, 2014)、对居民影响(马仁锋等, 2015; 湛东 升等, 2017)、与经济的关系(李双江等, 2013)等。其 中, “人居环境评价研究”的成果最为丰富。在城市 尺度,不少学者重点关注人居环境客观评价(宁越 敏等, 1999)或主观评价(李王鸣等, 1999); 在区域尺 度,有学者对京津冀地区(杨雪等, 2016)及辽宁省各 城市(晋培育等, 2011; 李雪铭等, 2014)等区域的人 居环境进行评价; 在全国尺度,也有部分学者通过 构建人居环境评价指标体系对全国城市人居环境 质量进行测度(封志明等, 2008; 李雪铭等, 2012; 湛 东升等, 2015; 李陈, 2017)。

城市人居环境包括人居硬环境和软环境两类 (宁越敏等, 1999)。梳理以上研究可以发现, 已有的 人居环境评价研究主要局限于城市人居硬环境的 评价, 而对城市人居软环境评价研究涉及较少, 针 对区域尺度的人居软环境评价则鲜有报道。在以 人为本的城市人居环境建设理念为导向, 如何将城 市人居硬环境评价与软环境评价相结合, 科学评估 城市人居环境建设成效是亟待解决的课题之一。 基于此, 本文以环渤海地区 44 个城市为例, 综合运 用统计年鉴数据和问卷调查数据, 对区域尺度城市 人居环境进行综合评价, 以期为加强环渤海地区人 居环境建设和提高居民对人居环境的满意度提供 科学启示。

\section{2 研究区域与数据来源}

\section{1 研究区概况}

环渤海地区包括河北、辽宁、山东 3 省和北京、 天津 2 个直辖市。土地面积面积 51.8 万 $\mathrm{km}^{2}$, 人口 2.54 亿人, 分别占全国土地总面积和总人口的 $5.4 \%$ 和 $18.5 \%$ (2014 年)。环渤海地区是中国北方经济总 量最大、人口最多的经济密集区, 2016年该地区生 产总值达到 16.37 万亿元, 占全国的 $22 \%$ 。但是, 该 地区也是中国环境污染最严重地区之一(王振波 等, 2015), 严重的污染对城市人居质量构成了重要 威胁, 因此探讨该区域城市人居环境质量具有重要 的实践意义。

\section{2 数据来源}

本文所用的统计数据主要来自《中国城市统计 年鉴 2015》, 其中 “燃气普及率” “用水普及率”来源 于《中国城市建设统计年鉴 2015》; “空气质量二级
以上天数占全年比例”来自各地市 2014 年国民经济 和社会发展统计公报和各省、市 2015 年统计年鉴; “人均 GDP”与 “人口数量” 来源于《中国统计年鉴 2015》; “城镇化率”来源于第六次全国人口普查; 问 卷调查数据来自宜居城市课题组于 2014 年对环渤 海城市的宜居调查。

\section{3 研究方法}

\section{1 城市人居环境评价指标构建}

城市人居环境包括人居硬环境和人居软环 境。其中, 人居硬环境是指城市实体物质环境; 而 人居软环境则主要强调非物质形态的社会文化和 制度环境。结合已有的城市人居环境评价成果(张 文忠等, 2015, 2016), 有形的人居硬环境更适用于 客观评价, 主要由居住条件、公共服务设施、交通便 捷性和环境宜人性等维度构成; 人居软环境属于无 形的非物质环境, 通常难以利用有效的客观指标进 行统计监测, 可采用问卷调查方式获取, 主要包括 社会文化环境和城市安全性等内容。本文基于科 学性、全面性、层次性、可比性和可获取性等原则, 结合客观评价和主观评价的各自优势对环渤海地 区城市人居环境内容进行综合评估,评价体系指标 如表 1 所示。

\section{2 城市人居环境评价方法}

城市人居硬环境的评价公式为:

$$
H H I_{i}=\sum_{j=1}^{m}\left(W_{i j} \times N_{i j}\right)
$$

式中: $H H I_{i}$ 为 $i$ 市人居硬环境指数, 即人居硬环境指 数; $m$ 为评价指标 $j$ 个数; $W_{i j}$ 为第 $j$ 项指标的权重值, 由专家打分法和层次分析法相结合获得; $N_{i j}$ 为第 $j$ 项指标的归一化之后的数值。人居软环境评价采 用 2014 年环渤海各市宜居城市的问卷调查数据。 此次调查以城市规模为主要标准设定样本数量, 按 照直辖市 300 份、省会和副省级城市 250 份、其他城 市根据规模大小各发放 200 或 150 份问卷, 共发放 问卷 7500 份, 回收有效问卷 6965 份, 有效率 $93 \%$ 。 该问卷内容包括有关宜居城市的 7 个方面, 从中篎 选出符合人居环境的 9 个指标, 涉及城市社会、文 化、管理等方面,采用 9 个问题的调查结果(表 2 )作 为城市人软环境的评价基础。问题中涉及 5 个选 项, 即: “很不满意” “比较不满意” “一般” “比较满 意” 和 “非常满意”。按照百分制分别对该 5 个选项 
表 1 城市人居环境综合评价体系

Tab.1 Comprehensive evaluation system of human settlement environment

\begin{tabular}{|c|c|c|c|}
\hline 目标层 & 准则层 & 指标层 & 单位 \\
\hline \multirow{17}{*}{$\begin{array}{l}\text { 人居 硬 } \\
\text { 环境 }\end{array}$} & \multirow[t]{3}{*}{ 居住条件 } & 人均居住面积 & $\mathrm{m}^{2}$ \\
\hline & & 燃气普及率 & $\%$ \\
\hline & & 用水普及率 & $\%$ \\
\hline & \multirow[t]{5}{*}{ 公共服务设施 } & 每百人公共图书馆藏书 & 册 \\
\hline & & 每万人医院床位数 & 张 \\
\hline & & 每万人普通中学数 & 所 \\
\hline & & 互联网普及率 & $\%$ \\
\hline & & 每百人拥有移动电话数 & 部 \\
\hline & \multirow[t]{3}{*}{ 交通便捷性 } & 每万人拥有出租车数量 & 辆 \\
\hline & & 人均道路面积 & $\mathrm{m}^{2}$ \\
\hline & & 每万人拥有公共汽车 & 辆 \\
\hline & \multirow[t]{6}{*}{ 环境宜人性 } & 建成区绿化覆盖率 & $\%$ \\
\hline & & 人均公园绿地面积 & $\mathrm{m}^{2}$ \\
\hline & & 人均烟粉尘排放量 & $\mathrm{t}$ \\
\hline & & 人均工业废水排放量 & $\mathrm{t}$ \\
\hline & & 人均工业二氧化硫排放量 & $\mathrm{t}$ \\
\hline & & $\begin{array}{l}\text { 空气质量二级以上天数 } \\
\text { 占全年比例 }\end{array}$ & $\%$ \\
\hline \multirow{14}{*}{$\begin{array}{l}\text { 人 居 软 } \\
\text { 环境 }\end{array}$} & \multirow[t]{8}{*}{ 社会文化环境 } & 城市特色文化氛围 & 满意度 \\
\hline & & 市民文化素质 & 满意度 \\
\hline & & & $1 \sim 5$ 分 \\
\hline & & 社会包容性 & $\begin{array}{l}\text { 满意度 } \\
1 \sim 5 \text { 分 }\end{array}$ \\
\hline & & 城市归属感 & 满意度 \\
\hline & & & $1 \sim 5$ 分 \\
\hline & & 历史文脉保护 & 满意度 \\
\hline & & & $1 \sim 5$ 分 \\
\hline & \multirow[t]{6}{*}{ 城市安全性 } & 交通安全 & 满意度 \\
\hline & & & $1 \sim 5$ 分 \\
\hline & & 社会治安 & 满意度 \\
\hline & & & $1 \sim 5$ 分 \\
\hline & & 防灾应急能力 & 满意度 \\
\hline & & & 1 5 分 \\
\hline
\end{tabular}

表 2 各准则层评价结果分析

Tab.2 Analysis results of sub-indices for the

Bohai Rim area

\begin{tabular}{lcccc}
\hline \multicolumn{1}{c}{ 准则层 } & 平均值 & 最大值 & 最小值 & 标准差 \\
\hline 居住条件 & 0.599 & 0.928 & 0.219 & 0.139 \\
公共服务设施 & 0.367 & 0.656 & 0.094 & 0.160 \\
交通便捷性 & 0.273 & 0.789 & 0.054 & 0.141 \\
环境宜人性 & 0.467 & 0.800 & 0.247 & 0.140 \\
社会文化环境 & 0.480 & 0.979 & 0.081 & 0.196 \\
\hline
\end{tabular}

赋值为: $0 、 30 、 60 、 80 、 100$,计算最终的人居软环境 的评价得分。公式为:

$$
\begin{aligned}
Q t_{i}= & \left(C_{i} \times 100+D_{i} \times 80+E_{i} \times 60+F_{i} \times 30+G_{i} \times 0\right) / \\
& \left(I_{i}-H_{i}-B_{i}\right)
\end{aligned}
$$

式中: $Q t_{i}$ 为第 $i$ 个指标的总体满意度评价值; $C_{i}$ 、 $D_{i} 、 E_{i} 、 F_{i} 、 G_{i}$ 分别代表调查问卷中回答“非常满 意”、“比较满意”、“一般”、“比较不满意”和“非常不 满意” 的样本个数; $I_{i}$ 为调查总样本数; $H_{i}$ 为选择 “不 了解”的样本数; $B_{i}$ 为缺填的样本数。求得各个指标 的评价值后, 根据式(3)进一步求得城市人居软环境 指数。

$$
S H I_{i}=\sum_{j=1}^{n}\left(w_{j} \times N Q t_{i j}\right)
$$

式中: $S H I_{i}$ 表示 $i$ 城市的人居软环境指数; $n$ 表示指 标个数; $w_{j}$ 代表第 $j$ 个系统的权重, 由专家打分法和 层次分析法相结合获得; $N Q t_{i j}$ 代表第 $i$ 个城市第 $j$ 个 指标的标准化之后的得分。据此可以计算得到环 渤海地区各城市的人居软环境指数。

\section{3 人居硬环境和软环境综合评价}

综合评价公式为:

$$
\mathrm{HSCI}_{i}=\alpha \times \mathrm{HHI}_{i}+\beta \times S H I_{i}
$$

式中: $H S C I_{i}$ 代表 $i$ 城市人居环境综合指数; $H H I_{i}$ 代 表 $i$ 城市人居硬环境指数; $S H I_{i}$ 代表 $i$ 城市人居软环 境指数, $\alpha$ 和 $\beta$ 分别为两者的权重。本文认为人居硬 环境和软环境同等重要,因此取 $\alpha=\beta=0.5$ 。

\section{4 结果分析}

\section{1 城市人居环境分维度评价}

用ArcGIS 10.3 的自然断点法对各准则层的得 分进行分级(图 1)。从准则层分析,各地级市在不同 的准则层的评价结果具有明显差异:平均值方面, 环渤海城市在居住条件维度的得分平均值最高, 为 0.599(表2), 而在交通便捷性维度的平均得分最低, 为 0.273 ; 标准差方面,社会文化环境的得分标准差 最大(0.196); 而居住条件得分的标准差最小,城市 间差异最小 $(0.139)$; 空间分布方面, 河北省的中南 部和山东省南部的城市在各个准则层的评分中大 部位于一般以下水平,而辽东湾和山东半岛的城市 在大部分准则层的得分位于较高以上水平。

将环渤海各个城市分为重要城市 (副省级以上 及省会城市)与非重要城市(除重要城市之外的其他 城市), 进一步分析可以发现: 重要城市在公共服务 

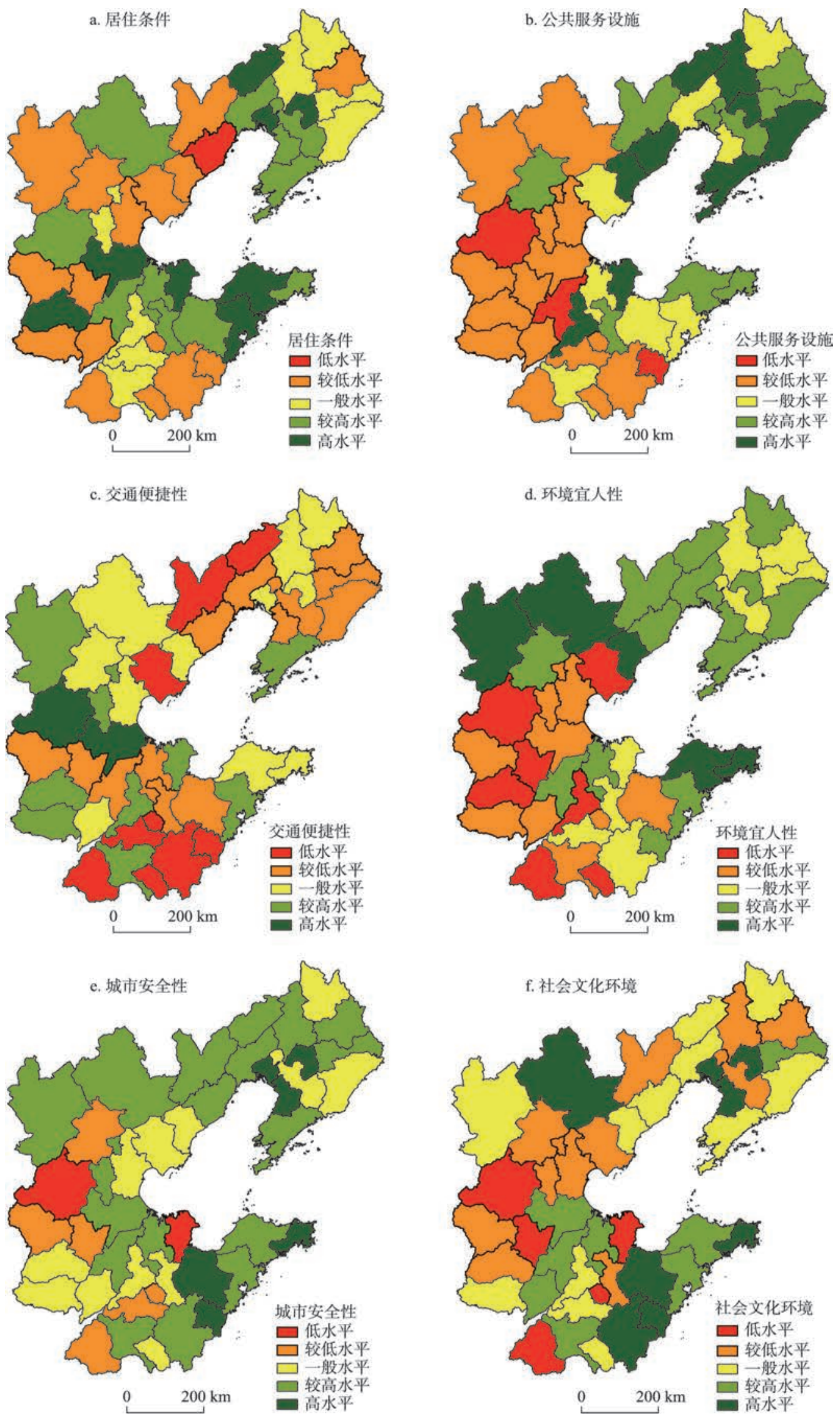

图 1 不同维度的人居环境评价结果

Fig.1 Evaluation result of human settlement environment with different sub-indices for the Bohai Rim area 
设施水平和交通便捷性两项评分中的平均值高于 非重要城市, 而在居住条件、环境宜人性、社会文化 环境和城市安全性评分的平均值均低于非重要城 市。重要城市的行政地位较其他城市高, GDP 总量 也位列各省级行政区内前列, 并有更多的财政投人 公共服务设施以及交通的建设, 但同时也会吸引周 围大量的人员进人, 造成环境污染和居住条件的下 降; 此外, 更加复杂的人员结构也会导致更多的社 会矛盾, 从而使得社会文化环境质量下降, 城市安 全性也会降低。因此, 城市规模对人居环境的影响 存在正反两方面效应。

\section{2 城市人居环境综合评价}

\subsection{1 硬环境综合评价}

根据式(1)计算得环渤海城市的人居硬环境指 数, 在 ArcGIS 10.3 中进行可视化, 利用自然断点法 进行分级得到图 2。通过总体数据分析, 可发现环 渤海各市的人居硬环境指数普遍不高, 所有城市的 人居硬环境指数都未超过 0.60 , 其人居硬环境指数 平均得分为 0.426 , 标准差为 0.09 。其中, 威海市是 人居硬环境质量最好的城市, 其人居硬环境指数达 0.58 ; 而束庄市是人居硬环境指数最低的城市, 仅为 0.251 , 极差值为 0.329 。在省级行政区层面, 辽宁省 是人居硬环境指数平均值最高的地区, 其平均值达 0.471 ; 而天津市则是人居硬环境指数最低的地区, 为 0.325 。

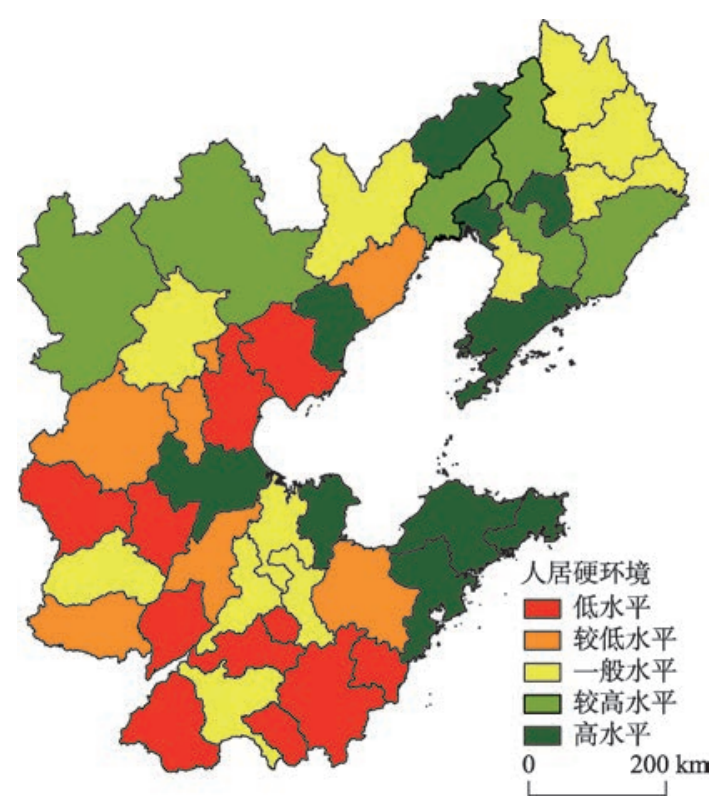

图 2 人居硬环境评价结果

Fig.2 Evaluation result of "hard" environment of human settlements for the Bohai Rim area
在总体空间分布方面, 人居硬环境质量较高的 城市主要集聚在山东半岛、辽宁省南部和中部、河 北省北部,而人居硬环境质量较低的城市主要集中 分布在河北省中南部和山东省南部。而在重要城 市中, 青岛市和大连市的人居硬环境指数处于高水 平, 而天津市和石家庄市的人居硬环境指数处于较 低水平, 其他大城市的人居硬环境指数则属于一般 水平。如将环渤海城市分为沿海城市和非沿海城 市, 可以发现: 沿海城市的平均硬环境指数为 0.467 ,显著高于非沿海城市的人居硬环境指数的平 均值, 说明人居硬环境质量存在沿海效应。

\subsection{2 软环境综合评价}

根据式(2)计算得到环渤海地区各城市的人居 软环境指数, 在 ArcGIS 10.3 中进行可视化, 利用自 然断点法进行分级得到图 3。总体来看, 环渤海地 区人居软环境指数平均值为 0.505 , 标准差为 0.182 。相对于人居硬环境指数而言, 人居软环境指 数的平均值较高, 但城市之间的差异更大。其中, 威海市是人居软环境质量最好的城市, 其人居软环 境指数达 0.99 , 而位居最后一名的东营市人居软环 境指数只有 0.075 , 极差值高达 0.915 。从图 3 中可 以看出, 人居软环境质量位于较高以上水平的城市 主要集聚于山东半岛地区, 而人居软环境较低的城 市则集中分布在河北省中部和南部、山东省中部。 在省级行政区尺度, 人居软环境指数平均值最高的

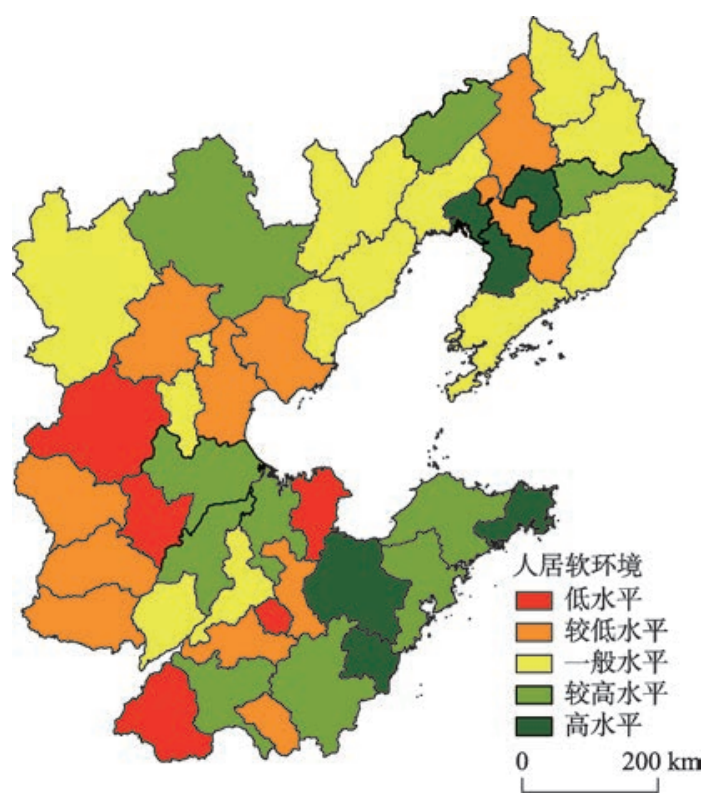

图 3 人居软环境评价结果

Fig.3 Evaluation result of "soft" environment of human settlements for the Bohai Rim area 
地区为辽宁省, 其均值达 0.561 ; 而人居软环境质量 最差的为北京市,其人居软环境指数仅为 0.345 。

除天津、石家庄外, 其他重要城市的人居软环 境评价结果的排名远远落后于其人居硬环境的排 名; 在重要城市中, 只有青岛市的人居软环境指数 达到较高水平。可见对于大城市而言, 人居软环境 成为人居环境建设的短板。其原因为:一方面, 大 城市相对小城市来说流动人口数量多, 人口成分较 为复杂,有可能产生比较多的社会问题;另一方面, 大城市的居民一般生活较为富足,城市的功能更为 丰富, 相应地对人居软环境也就提出了更高的要 求。因此, 大城市亟待提升城市管理水平, 构建和 谐的社会文化氛围, 维护稳定的社会秩序, 才能建 设成以人为本的宜居都市。

\subsection{3 城市人居环境综合评价结果}

将人居硬环境指数与人居软环境指数按照式 (3)加权后可得到人居环境综合指数, 利用 ArcGIS 10.3 自然断点法将合人居环境指数分为以下五类: “低水平” “较低水平” “一般水平” “较高水平”和“高 水平”, 见图 4。总体来看, 环渤海地区各城市综合 人居环境指数平均值为 0.466 , 标准差为 0.113 。综 合人居环境指数最高的城市为威海市, 最低的为菏 泽市。空间分布方面, 人居环境综合质量水平在空 间上呈现“东高西低” 的空间格局, 即: 辽东半岛和 山东半岛的人居环境综合质量较高; 而河北省南

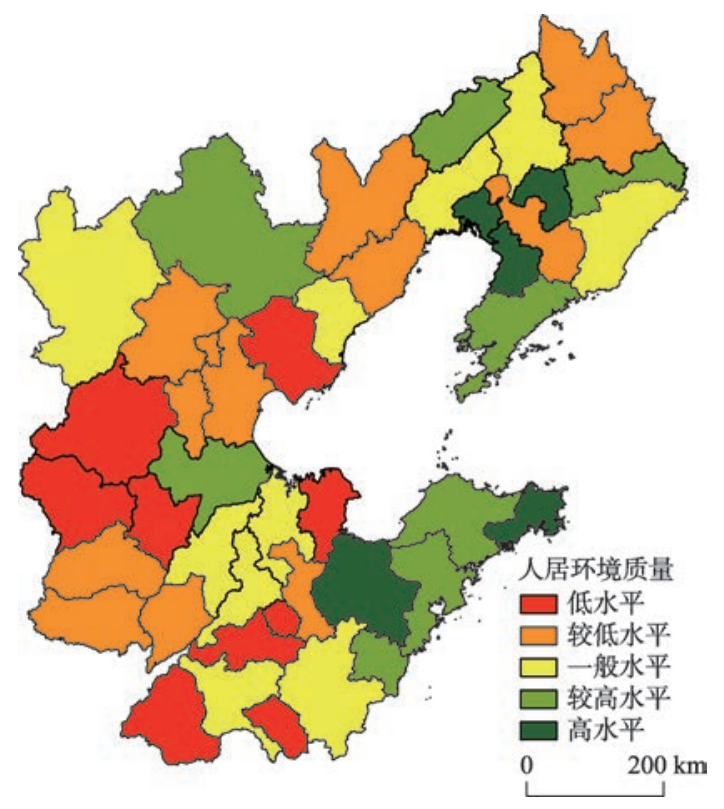

图 4 人居环境综合评价结果

Fig.4 Integrated evaluation result of human settlement environment for the Bohai Rim area
部、京津唐地区和山东省西部地区的人居环境综合 质量较低。总体而言, 人居环境综合指数存在沿海 效应, 5 个人居环境综合质量高水平的城市有 4 个 是沿海城市; 13 个人居环境综合质量较高水平的城 市有 10 个属于沿海城市。在 3 省 2 市中, 辽宁省各 个城市人居环境综合指数的平均值最高, 为 0.516 ; 而天津市的人居环境综合指数最低, 仅为 0.376 。

在环渤海地区重要城市中, 人居环境综合指数 普遍较低, 仅青岛市和大连市的人居环境综合指数 达到较高水平, 表明: 城市经济的发达程度并不一 定与人居环境的舒适度相匹配。

\section{3 城市人居环境相关因素分析}

由于人居环境受到多方面因素影响, 因此本文 对人居环境评价结果与人均 GDP 和人口总数进行 相关性分析, 探究经济发展水平与城市规模对人居 环境质量的影响。利用RStudio对环渤海地区各城 市的居住条件得分、公共服务设施得分、交通便捷 性得分、环境宜人性得分、社会文化环境得分、城市 安全性得分、人居硬环境指数、人居软环境指数和 人居环境综合指数分别与人均 GDP、人口规模和城 镇化水平进行 spearman 相关性分析, 结果如表 3 。

总体来看, 人居硬环境指数与人均 GDP 和城镇 化水平之间存在着显著的正相关性, 意味着经济发 展水平和城镇化率越高, 人居硬环境指数越高。因 为城市的经济发展和城镇化率提高会带来更多的 经济效益,政府也就可能提供更多的税收投人公共 设施建设以及污染治理等,而这些措施又可促进人 居硬环境质量得到进一步提升。人居硬环境指数 与人口数量之间存在负相关性, 意味着人口越多人 居硬环境综合指数越低。人口数量过度增加可能 会带来一系列社会问题, 导致有限的公共资源被大

表 3 相关性分析结果

Tab.3 Result of correlation analysis

\begin{tabular}{lccc}
\hline \multicolumn{1}{c}{ 相关分析项 } & 人均 GDP & 人口规模 & 城镇化水平 \\
\hline 居住条件 & $0.280^{*}$ & -0.203 & 0.183 \\
公共服务设施 & $0.416^{* * *}$ & $-0.454^{* * *}$ & $0.572^{* * *}$ \\
交通便捷性 & 0.088 & $0.289^{* *}$ & 0.060 \\
环境宜人性 & 0.208 & $-0.455^{* * *}$ & 0.245 \\
社会文化环境 & 0.112 & -0.197 & -0.001 \\
城市安全性 & 0.204 & $-0.308^{* *}$ & 0.130 \\
人居硬环境指数 & $0.355^{* *}$ & $-0.353^{* *}$ & $0.404^{* * * *}$ \\
人居软环境指数 & -0.006 & -0.249 & 0.034 \\
人居环境综合指数 & 0.228 & $-0.303^{* * *}$ & 0.195 \\
\hline
\end{tabular}

注: ***、**、*分别表示在 $0.01 、 0.05 、 0.10$ 水平下显著。 
量占用, 造成城市用地、公共设施供给紧张, 给城市 人居硬环境带来负面效应。人居软环境指数与人 均 GDP 和城镇化水平不存在显著相关关系, 这就意 味着经济的发展、城镇化水平提高不一定会带来人 居软环境质量的改善。因此,经济发达的城市也必 须相应地加强城市安全和社会文化建设, 丰富市民 的精神生活,才能切实提高人居软环境的质量。

受到人居硬环境和软环境两方面的影响, 人居 环境综合指数与人均 GDP 和城镇化率不存在显著 的正相关关系, 而与人口数量呈显著的负相关关 系。由此表明城市人口数量的增加有可能造成人 居环境质量的下降。因此, 要想提高城市人居环境 质量, 必须控制人口数量的无序增长, 避免城市的 盲目扩张。

\section{5 结论与讨论}

本文以环渤海地区城市为例, 将区域尺度人居 环境客观评价与主观评价相结合,综合评估环渤海 地区城市人居环境质量, 可为促进环渤海地区城市 人居环境建设提供决策科学依据。主要研究结论 如下:

(1) 人居硬环境质量在空间格局上具有沿海效 应, 沿海的城市人居硬环境指数普遍高于内陆城 市。根据相关性分析, 人均 GDP 的提升有助于改善 人均硬环境质量, 而人口的快速增加则会导致人均 硬环境的降低。

(2) 人居软环境指数与经济发展水平、城镇化 水平不存在显著的相关关系, 经济水平和城镇化率 的提升并不一定会带来人居软环境的改善。另外, 在 7 个省会城市和副省级以上城市中, 只有青岛市 的人居软环境指数达到较高水平, 可见对于大城市 而言, 人居软环境成为人居环境建设的短板。因 此, 如何在发展经济提升人居硬环境质量的同时进 一步提升人居软环境质量是大城市面临的重要 课题。

(3) 环渤海地区的人居环境综合指数呈现 “东 高西低”的空间格局。辽东半岛和山东半岛高, 河 北中部低。人居环境综合指数同样也具有沿海效 应, 沿海城市的人居环境综合指数普遍高于内陆城 市。相关性分析发现, 人居环境综合指数与经济发 展水平和城镇化率不存在显著的正相关关系, 而与 城市的人口数量存在显著的负相关关系。
综上所述,环渤海地区各城市的人居环境质量 水平还有很大的提升空间。环渤海地区人口数量 多, 人口密度大, 人口分布极为不均, 主要集中在北 京、天津等个别特大和超大城市, 导致其人居资源 占有量低,使其相对于其他城市面临着更大的人居 环境压力。因此,环渤海地区应按照国家新型城镇 化规划和京津冀协同发展战略,疏解北京等大城市 的人口和职能, 既可带动和促进周围地区的发展, 也可控制人口规模,有利于提高人居环境水平;而 周围的中小城市则要培育发展新兴产业、加大公共 基础设施投人,改善生态环境,营造更宜居、更和谐 的人居环境。

\section{参考文献(References)}

封志明, 唐焰, 杨艳昭, 等. 2008. 基于 GIS 的中国人居环境指 数模型的建立与应用 $[J]$. 地理学报, 63(12): 1327-1336. [Feng Z M, Tang Y, Yang Y Z, et al. 2008. Establishment and application of human settlements environment index model (HEI) based on GIS[J]. Acta Geographica Sinica, 63 (12): 1327-1336.]

谷永泉, 杨俊, 冯晓琳, 等. 2015. 中国典型旅游城市人居环 境适宜度空间分异研究 [J]. 地理科学, 35(4): 410-418. [Gu Y Q, Yang J, Feng X L, et al. 2015. Spatial differentiation of human settlement environment suitability in Chinese typical tourist cities[J]. Scientia Geographica Sinica, 35(4): 410-418.]

晋培育, 李雪铭, 冯凯. 2011. 辽宁城市人居环境竞争力的时 空演变与综合评价[J]. 经济地理, 31(10): 1638-1644. [Jin P Y, Li X M, Feng K. 2011. The spatial-temporal and evaluation evolvement of the urban settlement environment competitiveness of Liaoning Province[J]. Economic Geography, 31(10): 1638-1644.]

李伯华, 刘沛林, 窦银娣. 2014. 乡村人居环境系统的自组织 演化机理研究 [J]. 经济地理, 34(9): 130-136. [Li B H, Liu P L, Dou Y D. 2014. Analysis of self-organizing evolution mechanism of rural human settlement system[J]. Economic Geography, 34(9): 130-136.]

李陈. 2017. 中国 36 座中心城市人居环境综合评价 [J]. 干旱 区资源与环境, 31(5): 1-6. [Li C. 2017. Comprehensive evaluation of human settlements in 36 central cities of Chi$\mathrm{na}[\mathrm{J}]$. Journal of Arid Land Resources and Environment, 31 (5): 1-6.]

李双江, 胡亚妮, 崔建升, 等. 2013. 石家庄经济与人居环境 耦合协调演化分析[J]. 干旱区资源与环境, 27(4): 8-15. [Li S J, Hu Y N, Cui J S, et al. 2013. Evolvement of coupling coordination between economic and human settle- 
ment environmental systems in Shijiazhuang City[J]. Journal of Arid Land Resources and Environment, 27(4): 8-15.] 李王鸣, 叶信岳, 孙于. 1999. 城市人居环境评价: 以杭州城 市为例 [J]. 经济地理, 19(2): 38-43. [Li W M, Ye X Y, Sun Y. 1999. The assessment of urban human settlements: A case study of Hangzhou[J]. Economic Geography, 19(2): 38-43.]

李雪铭, 晋培育. 2012. 中国城市人居环境质量特征与时空 差异分析[J]. 地理科学, 32(5): 521-529. [Li X M, Jin P Y. 2012. Characteristics and spatial-temporal differences of urban human settlement environment in China[J]. Scientia Geographica Sinica, 32(5): 521-529.]

李雪铭, 田深圳, 杨俊, 等. 2014. 城市人居环境的失配度: 以 辽宁省 14个市为例 [J]. 地理研究, 33(4): 687-697. [Li X M, Tian S Z, Yang J, et al. 2014. The preliminary study of mismatch degree of urban human settlements: Taking 14 cities in Liaoning Province as cases[J]. Geographical Research, 33(4): 687-697.]

马仁锋, 王美, 张文忠, 等. 2015. 临港石化集聚对城镇人居 环境影响的居民感知: 宁波镇海案例 [J]. 地理研究, 34 (4): 729-739. [Ma R F, Wang M, Zhang W Z, et al. 2015. Residents' perceptions of the impact on urban human settlements from petrochemical industry cluster in port area: Case study of Zhenhai District[J]. Geographical Research, 34(4): 729-739.]

宁越敏, 查志强. 1999. 大都市人居环境评价和优化研究: 以 上海市为例 [J]. 城市规划, 23(6): 15-20. [Ning Y M, Zha Z Q. 1999. The study of evaluation and optimization for human settlement in the metropolitan areas: Take Shanghai as an example[J]. City Planning Review, 23(6): 15-20.]

祁新华, 程显, 陈烈, 等. 2008. 大城市边缘区人居环境系统 演变规律: 以广州市为例 [J]. 地理研究, 27(2): 421-430. [Qi X H, Cheng Y, Chen L, et al. 2008. The evolvement rules of human settlements system on metropolis fringe: A case study of Guangzhou[J]. Geographical Research, 27 (2): 421-430.]

汪洋, 赵万民. 2012 . 人居环境研究的信息论科学基础及其 图谱意象系统 [J]. 地理学报, 67(2): 253-265. [Wang Y, Zhao W M. 2012. Information theory for human settlements research and its info-spectrum images system[J]. Acta Geographica Sinica, 67(2): 253-265.]

王振波, 方创琳, 许光, 等. 2015. 2014 年中国城市 $\mathrm{PM}_{2.5}$ 浓度 的时空变化规律 [J]. 地理学报, 70(11): 1720-1734. [Wang Z B, Fang C L, Xu G, et al. 2015. Spatial-temporal characteristics of the $\mathrm{PM}_{2.5}$ in China in 2014[J]. Acta Geographica Sinica, 70(11): 1720-1734.]

吴良镛. 2001. 人居环境科学导论 [M]. 北京: 中国建筑工业 出版社. [Wu L Y. 2001. Introduction to sciences of human
settlements[M]. Beijing, China: China Architecture \& Building Press.]

杨雪, 张文忠. 2016. 基于栅格的区域人居自然和人文环境 质量综合评价: 以京津冀地区为例 [J]. 地理学报, 71(12): 2141-2154. [Yang X, Zhang W Z. 2016. Combining natural and human elements to evaluate regional human settlements quality based on raster data: A case study in BeijingTianjin-Hebei region[J]. Acta Geographica Sinica, 71(12): 2141-2154.]

湛东升, 张文忠, 党云晓, 等. 2015. 中国城市化发展的人居 环境支撑条件分析 [J]. 人文地理, 30(1): 98-104. [Zhan D S, Zhang W Z, Dang Y X, et al. 2015. An analysis of supporting conditions of living environment for urbanization development in China[J]. Human Geography, 30(1): 98104.]

湛东升, 张文忠, 党云晓, 等. 2017. 中国流动人口的城市宜居 性感知及其对定居意愿的影响 [J]. 地理科学进展, 36 (10): 1250-1259. [Zhan D S, Zhang W Z, Dang Y X, et al. 2017. Urban livability perception of migrants in China and its effects on settlement intention[J]. Progress in Geography, 36(10): 1250-1259.]

张文忠, 谌丽, 杨翌朝. 2013. 人居环境演变研究进展 $[\mathrm{J}]$. 地 理科学进展, 32(5): 710-721. [Zhang W Z, Chen L, Yang Y Z. 2013. Research progress on human settlement evolution[J]. Progress in Geography, 32(5): 710-721.]

张文忠, 余建辉, 李业锦, 等. 2015 . 人居环境与居民空间行 为 $[\mathrm{M}$ ]. 北京: 科学出版社. [Zhang W Z, Yu J H, Li Y J, et al. 2015. Human settlement and spatial behavior of residents[M]. Beijing, China: Science Press.]

张文忠, 余建辉, 湛东升, 等. 2016. 中国宜居城市研究报告 [M]. 北京: 科学出版社. [Zhang W Z, Yu J H, Zhan D S, et al. 2016. A study of livable cities in China[M]. Beijing, China: Science Press.]

朱涁, 张小林, 尹旭. 2015. 江苏省乡村人居环境质量评价及 空间格局分析 [J]. 经济地理, 35(3): 138-144. [Zhu B, Zhang X L, Yin X. 2015. Evaluation of rural human settlements quality and its spatial pattern in Jiangsu Province[J]. Economic Geography, 35(3): 138-144.]

Castro C P, Ibarra I, Lukas M, et al. 2015. Disaster risk construction in the progressive consolidation of informal settlements: Iquique and Puerto Montt (Chile) case studies[J]. International Journal of Disaster Risk Reduction, 13: 109127.

Charoenkit S, Kumar S. 2014. Environmental sustainability assessment tools for low carbon and climate resilient low income housing settlements[J]. Renewable and Sustainable Energy Reviews, 38: 509-525.

Doxiadis C A. 1975. Action for human settlements[M]. Ath- 
ens, Greece: Athens Publishing Center.

Jackson R J, Dannenberg A L, Frumkin H. 2013. Health and the built environment: 10 years after[J]. American Journal of Public Health, 103(9): 1542-1544.

McNeill L H, Kreuter M W, Subramanian S V. 2006. Social environment and physical activity: A review of concepts and evidence[J]. Social Science \& Medicine, 63(4): 10111022.

Reeves D. 2014. Putting women and gender in the frame: A consideration of gender in the Global Report on Human Settlement Planning Sustainable Cities 2009[J]. Habitat International, 43: 293-298.

Schetke S, Haase D, Kötter T. 2012. Towards sustainable settlement growth: A new multi-criteria assessment for implementing environmental targets into strategic urban planning
[J]. Environmental Impact Assessment Review, 32(1): 195210.

Sebti M, Alkama D, Bouchair A. 2013. Assessment of the effect of modern transformation on the traditional settlement 'Ksar' of Ouargla in southern Algeria[J]. Frontiers of Architectural Research, 2(3): 322-337.

Tsinda A, Abbott P, Chenoweth J. 2015. Sanitation markets in urban informal settlements of East Africa[J]. Habitat International, 49: 21-29.

United Nations. 1976. The Vancouver declaration on human settlements[J]. Nairobi: UN Habitat.

Yen I H, Kaplan G A. 1999. Neighborhood social environment and risk of death: Multilevel evidence from the Alameda County study[J]. American Journal of Epidemiology, 149 (10): 898-907.

\title{
Quantitative evaluation of human settlement environment and influencing factors in the Bohai Rim area
}

\author{
CHEN Chengyi ${ }^{1,2}$, ZHANG Wenzhong $^{1^{*}}$, ZHAN Dongsheng ${ }^{1,2}$, LI Xueli $^{3}$ \\ (1. Institute of Geographic Sciences and Natural Resources Research, CAS, Beijing 100101, China; \\ 2. University of Chinese Academy of Sciences, Beijing 100049, China; 3. School of International Business \\ Administration, Shanghai University of Finance and Economics, Shanghai 200433, China)
}

\begin{abstract}
Urban human settlement environment plays a very important role in the life quality and satisfaction of urban residents. This study employed descriptive statistics and GIS mapping methods to analyze the spatial heterogeneity and socioeconomic influencing factors of human settlement environment in the Bohai Rim area. The conclusions are as follows. There are significant spatial heterogeneities in "hard" human settlement environment index (HHI), "soft" human settlement environment index (SHI), and human settlement environment quality composite index (HSCI). The quality of human settlement environment in coastal cities is significantly higher than that in inland cities. For the provincial administrative units, Liaoning has the highest HSCI; HSCI in Tianjin is the lowest. The correlation analysis between socioeconomic factors and HSCI further shows that there is no significant positive correlation between the HSCI values and the level of economic development and urbanization in the Bohai Rim area-more prosperous economy and higher urbanization rate cannot bring in higher quality of human settlement environment; but there is a significant negative correlation between the HSCI and population in the Bohai Rim area. Therefore the control of urban population in the region will be helpful for improving the quality of human settlement environment.
\end{abstract}

Key words: human settlement; Bohai Rim area; integrated evaluation; socioeconomic factors 